\title{
A METHODOLOGICAL APPROACH TO MANAGE WEEE RECOVERY SYSTEMS IN A PUSH/PULL LOGIC
}

\author{
Mosè Gallo \\ Elpidio Romano \\ Liberatina C. Santillo \\ University of Naples "Federico II" \\ Tecchio Square \\ Naples, 80125, ITALY
}

\begin{abstract}
This work aims at establishing a new management paradigm for Waste Electrical and Electronic Equipment (WEEE) collection and treatment networks, based on Lean Thinking methodological approaches. The objective is to maximize the WEEE recovery rate to effectively support the production of new products, creating on one side the conceptual basis of the Closed Loop Supply Chain, and on the other side minimizing the environmental impact of production processes in exploiting natural resources. The achievement of such results is supported by the application of a System Dynamics simulation approach.
\end{abstract}

\section{INTRODUCTION}

Nowadays, Electrical and Electronic Equipment (EEE) characterize every aspect of our daily lives, by improving the standard of living. Unfortunately, the continuous technological innovations and the growing consumerism accelerate the rate at which these products are replaced, causing the exponential increase in the production of Waste Electrical and Electronic Equipment (WEEE). The production process of EEE requires a large amount of substances that represents a potential threat to environment and human health if they are not recovered or disposed of properly.

This situation has turned on the environmental awareness of consumers and sensitized legislators from different countries to enact and implement specific laws and directives for the management of the end of the life cycle of these products and to regulate the employment of hazardous materials in these products. The approach of the legislators, however, is reactive: it forces to manage the problem of waste from EEE rather than eliminate it at the source through proactive approaches that would allow for designing the recoverability of the end of life product. In fact, although they represent a threat, WEEE are, at the same time, a resource for companies that have to manage them, more if the recovery activities are properly integrated into the product' design phase (Design For Rx - DFRx and Design For Environment - DFE). The recovery process of parts, components and materials from WEEE enables companies both to limit their environmental impact and cut some production costs. It is clear, however, that a virtuous (proactive) management of the environmental problem linked to the EEE would require new design and, eventually, production approaches. In the short term, the producers strive to address the problem in a reactive way simply managing the waste and, possibly, integrating it in their production processes. A radical rethink of the product, however, which would allow greater management economies for production and logistics processes in the closed loop supply chain, must necessarily be a long-term goal for all companies that try to find opportunities where other companies see waste. In the present context, therefore, it has an important impact to face the problem of sorting these products, not being eco 
designed, in the most proper way. In that respect, this work aims at developing a management model of WEEE flows assessing and validating its possible outcomes in management terms.

First the closed loop supply chain theoretical approach is described in Section 2 to provide a theoretical framework and methodology for the problem formulation. Section 3 analyzes the state of the art of WEEE recovery and treatment. In Section 4, we define the methodological approach to reformulate the system of waste management according to Hybrid Push/Pull logic. In Section 5 we present the process that we followed to develop the System Dynamics simulation model, with the ability to validate the logical proposals. Finally in Section 6, performance data of the new reverse logistics network configuration is presented in a Future State Map.

\section{CLOSED LOOP SUPPLY CHAIN}

The term Closed Loop Supply Chain (CLSC) encloses all direct and reverse logistics tasks. Reverse (RL) logistics defines only those activities necessary to move the products back into the supply chain and to process them properly. Several operational and technical definitions of CLSC have been proposed by researchers and operators. It consists of the design, management and control a system able to maximize value creation along the entire product lifecycle. Although it does refer to the entire product lifecycle, an integrated approach of direct and reverse flow is not found in literature. For this reason the focus is often on the reverse supply chain.

The CLSC assumes different structures and operation modes depending on the type of returns processed and, therefore, on the recovery options adopted. Usually companies develop a reverse supply chain for coping with a mix of choices and returns are processed by taking the most profitable alternative (Shultman, Zumkeller, and Rentz 2006).

The activities of the CLSC can be grouped into five main sub-processes, which take a different priority based on the specific circumstances:

1. The acquisition includes the recovery of products at various points of use in the supply chain. An efficient recovery system requires a certain level of quality and quantity of the same products to pursue the economies of scale. In this phase, a close collaboration is required with other actors in the supply chain to reduce the uncertainties on quality, quantity and timing of returns. As much information as possible should be collected about products and their users to easily choose the most appropriate recovery option.

2. Reverse logistics including the following activities: transportation, warehousing, distribution, and inventory management. Also this phase should be carefully analyzed because the high costs of logistics can make the CLSC configuration not profitable. It is strongly debated in literature whether to use distribution centers separated for the forward and reverse logistics or a Centralized Returns Center (CRT), where the returns are managed centrally. Many authors, including Rogers and Tibben-Lembke (1999), prefer the latter alternative. However, in the distribution choices several issues should be considered including the priority of the reverse supply chain, regulatory constraints, product's characteristics, volumes, transport and processing costs, and the viable solutions. In recent years, many Third-Party Logistics providers have developed comprehensive integrated solutions for the RL and the companies can then choose to entrust them with the whole process.

3. Inspection and sorting: tests and checks are carried out to determine the quality of returns, and then the most appropriate recovery strategy is selected.

4. Recovery: depending on the recovery option, the proper activities are performed on the products or its parts and components.

5. Sales and Distribution. Direct channels can be used distinguishing between new and used products. Sometimes marketing efforts are necessary to convince consumers about the quality of recovered products. 


\section{WEEE MANAGEMENT SYSTEMS: LITERATURE REVIEW}

As mentioned before, the problem of managing goods' environmental sustainability throughout their life cycle can be addressed at different time scales: In the short term we focus on the reverse logistics network design and management and its integration with forward logistics; in the medium/long term, we can adopt a proactive logic, designing products with an increasing life-cycle for their parts and components due to the simpler reuse, remanufacturing or recycling options.

The reverse logistics network design and management, however, can be also considered as an experimental stage for new product design. In other words, the optimal location/allocation of recovery and treatment centers besides reducing WEEE landfill load, provides a valuable tool to identify those parts and components that are frequently reused and/or remanufactured, and those that can be only recycled. The data collected from the Reverse Logistics Network (RLN) management help to define the design of future products.

Several case studies have been carried out in order to study the different approaches to reverse logistics options. Carpet recycling logistics networks are addressed by Ammons, Realff, and Newton (1997) and Louwers et al. (1999). Spengler et al. (1997) examine the recycling of industrial by-products in German steel industry. Berger and Debaillie (1996) address the situation of recovery of used products. Krikke and Van Harten (1999) study the reverse logistic network for durable consumer products. We refer to Fleischmann et al. (1997) for a detailed discussion of this field. In literature, however, there are several management models for WEEE collection. Some papers use simulation techniques to validate the network design choices based on a discrete event logic or to serve as decision support tools (Bautista and Pereira 2006; Guerra, Murino, and Romano 2009). Other works use optimization techniques for the location/allocation of nodes having different function in the network (Guerra, Murino, and Romano 2009). In addition to discrete event simulation (DES) techniques, the problem is also addressed using the System Dynamics (SD) approach (Gallo, Murino, and Romano 2010). Some papers first give an overview of recent research work in these areas, followed by a discussion of research issues that have evolved, and represent a taxonomy of research and development in System Dynamics Modeling in supply chain Management (e.g., Georgiadis and Besiou 2008). Georgiadis and Vlachos (2004) explain the basic theory of the system modeling and utilize it for a reverse logistics model. They provide an illustrative example to show how SD modeling can be used to produce a powerful long-term decision-making tool.

Towill (1995) uses SD in supply chain redesign. Haffez et al. (1996) describe the analysis and SD modeling of a two-echelon supply chain encountered in the construction industry. Gonçalves, Hines, and Sterman (2005) incorporate endogenous demand in a hybrid push-pull production system model. Van Schaik and Reuter (2004) present an SD model focused on cars showing that the realization of the legislation targets imposed by European Union (EU) depends on the product design. Although SD has been applied for analysis of various environmental systems, many studies have studied environmental systems from a different approach. Specifically, Min and Galle (2001) present a survey of US firms to study the firm's perceived importance of regulations on the implementation of green purchasing. This work aims at establishing a new management paradigm for collection and treatment network from WEEE, based on Lean Thinking methodological approaches. The objective is to maximize the WEEE recovery rate to effectively support the production of new products, creating on one side the conceptual basis of the Closed Loop Supply Chain, and on the other side minimizing the production environmental impact in exploiting natural resources. The achievement of such results is supported by the application of system dynamics simulation logic. Discrete event simulation (DES) and system dynamics (SD) are two quite different approaches to simulation modeling. DES models systems as networks of queues and activities, where state changes in the system occur at discrete points of time. On the other hand system dynamics models a system as a series of stocks and flows, in which the state changes are continuous. An SD model captures the factors affecting the behavior of the system in a causal-loop diagram. This diagram clearly depicts the linkages and feedback loops among the elements in the system, as well as all pertinent linkages between the system and its operating environment. This type of analysis can be valuable to a decision-maker as an aid in understanding a complex, inter-related system. A DES model can replicate 
the performance of an existing system very closely and provide a decision-maker insights into how that system might perform if modified, or how a completely new system might perform. To achieve the fidelity to evaluate the performance of a real world process, a DES model requires accurate data on how the system operated in the past or accurate estimates on the operating characteristics of a proposed system. There are several reasons for which we prefer the SD approach to DES. The first is related to the width and the complexity the system under study: a WEEE collecting and treatment network is composed of various nodes and links representing themselves complex and interacting realities. The object of this study is to grasp the overall system behavior resulting from the nonlinear interactions of the system parts and adopt an approach that allows achieving our goals without the level of detail that would require a DES model. Moreover the problem at hand is characterized by an intrinsic retroactive nature that is replicated by the SD model and is also tackled by the lean thinking framework used for studying the problem.

\section{THE METHODOLOGICAL PROPOSAL}

The methodological proposal developed in this work is articulated into six steps that together develop an innovative management model for WEEE:

- Step I-Identification of the reverse logistics network. It is necessary to identify the set of nodes in the network and their links. In particular, two clusters will be considered, each characterized by the type of node: the first is represented by the WEEE collecting centers and the second envelops the treatment centers. These clusters are characterized by internal links and mutual interactions. The collection centers transfer the WEEE to the available treatment facilities.

- Step II - Definition of physical and information flows. Interactions between the nodes of the network can be physical and informative. The information flows concern both the inventory level control of the various collecting centers, and the requests (signals) to treatment facilities for the planning of the waste withdrawal. Information flows are accompanied by physical flows of WEEE from collection to treatment centers. The WEEE collection operation implies that when the end user needs to dispose of an EEE, he can choose between two different transfer modalities of the disposed goods: to call the door-to-door pickup service for bulky waste (the maximum waiting time is two business days, depending on whether the request has come before 12:00 noon or after this time), to transport the disposed product on their own to the closest collecting center. At the collecting center, end of life products are put in safety, if necessary, sorted into the groups defined by the directives and stocked in specific containers. The collecting center staff, when the maximum capacity of containers is reached, calls for a transfer of the full container to a treatment center by the transport companies. See figure 1.

- Step III - Representation of the current situation. In order to formulate designing quantitative alternatives for the reverse logistics network for minimizing the amount of untreated waste, we use a graphical tool known in literature as Value Stream Map. This instrument allows graphical mapping of the processes and activities involved in product recovery. The output of this step is the Current State Map (CSM).

- Step IV - Identification of critical issues in the system under study. The value chain analysis does not aim at improving the single process, but the global performance. With this method it is possible to categorize all activities, dividing them into those value-added and non-value added. All non-value added activities should be reduced and/or eliminated. From the analysis of the Current State Map, it is possible to identify the critical points that make the system inefficient (high transfer times, high times of storage, etc.).

- Step $V$-Resolution of critical situations. This activity is conducted through the formulation of alternative hypotheses for the reverse logistics network exceeding and/or solving the problems identified during the development of the Current State Map. The output of this step is the Future State Map (FSM) for the reverse logistics network. In general, the modification of the CSM into 


\section{Gallo, Romano, and Santillo}

the FSM is obtained by assuming some changes in the management logic of the system, for example, turning the PUSH management logic into a PULL or hybrid PUSH/PULL logic with the representation of the decoupling points based on a Supermarket Kanban PULL.

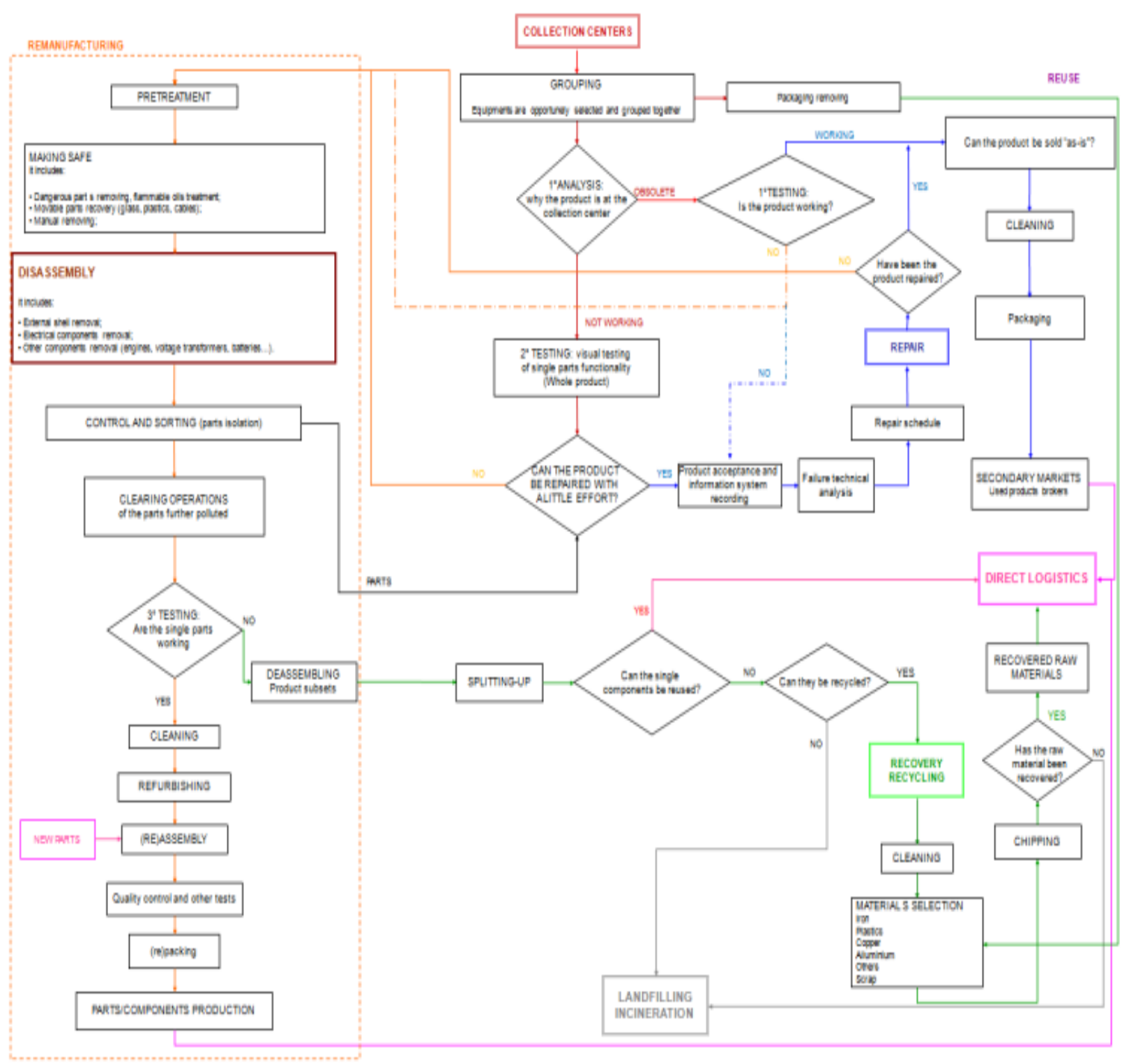

Figure 1: Flow chart of WEEE collecting process

- Step VI - Validation of the design solution proposed. The improvement proposals from the previous step have to be verified. For this purpose we use a simulation tool modeling the process of WEEE recovery and treatment according to the new management model. The computational complexity of the problem in study, further complicated by the presence of interrelated aspects, pushes toward the choice of a simulation approach based on dynamic logic (System Dynamics). The simulation model, allowing a performance analysis of the system, will quantify any improvements in the management of reverse logistics network. 


\section{MODEL IMPLEMENTATION}

The starting assumptions for the implementation of the model are:

1. The different citizens are aggregated in one single box for each different zone.

2. The collection centers in every zone are aggregated in a single node.

3. The door-to-door pickup service for bulky waste has a two days processing time on average.

4. The travelling time between the treatment centers and the recovery centers is calculated as the weighted average of the travelling times.

We first developed the Current State Map (see figure 2). It is possible to separate the activities linked to physical flows from those linked to information flows. In Table 1 we report the physical activities required from the waste generation until it reaches the treatment center.

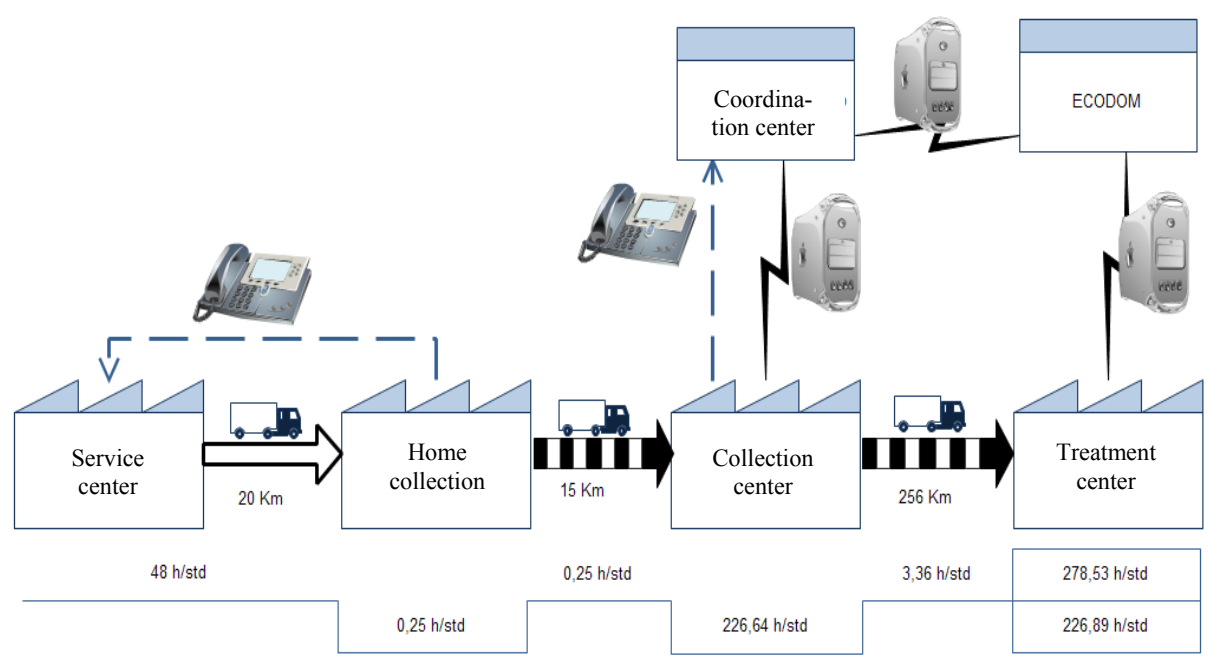

Figure 2: Current State Map

Table 1: Physical activities

\begin{tabular}{rc}
\hline Description of physical activities & Added Value \\
\hline WEEE waiting at collection center & NO \\
Waste load on the freight vehicles & YES \\
Waste transportation to the recovery center & YES \\
Putting in safety the potentially dangerous WEEE & YES \\
Waste stocking in proper container & YES \\
Waiting for container filling and picking & NO \\
Container load on freight transport vehicles & YES \\
Journey to the processing/recovery center & YES \\
\hline
\end{tabular}

The activities constituting the information flow are:

- call for a door-to-door pickup service

- call for a withdrawal of a full container

- order dispatching

- travel planning of full containers from the collecting centers to the treatment center

The analysis of the Current State Map data shows the huge impact of the added value activities with respect to the non-value added ones. Moreover, it is possible to highlight the presence of different kind of waste: in particular the waiting time for the waste collection at the collecting center is certainly the most 


\section{Gallo, Romano, and Santillo}

crucial and determinant "waste" producing weak system performances. This is a non-value added activity and its duration comprises $81 \%$ of the total time. Besides, the waiting time impacts also on the collecting center efficiency: in fact, the collecting center, which has already sent a picking request of a full container, cannot accept disposed products until its request is met. The waiting time for the waste to be collected at users' houses is another non-value added activity responsible for $17 \%$ of the total time Furthermore, it is possible to highlight an information flow fluidity problem in the process: the centralized management of pick-up requests from users weighs down the information flow. These issues lead to the specification of some improvements to the current management model. The starting idea comes up from the observation that the waste average waiting time at the collection center is certainly the major non-value added activity. This is consequent to the choice of a push strategy in the waste "picking/request" process. Actually this takes place only after the complete saturation of the center capacity.

The redesign idea consists in transforming this Reverse Logistics phase, from the collecting center to the treatment center, from a Push logic into a Pull one. The result is a hybrid Push/Pull system in which the waste is pulled by the recovery center and not pushed by the collecting center. The waste arrival at the collecting center is still push because it is non-predictable. For this purpose, a supermarket is introduced in the model and a Milk-Run strategy is defined (Guerra, Murino, and Romano 2007) for the waste withdrawal from the supermarket and from the distribution centers. Moreover, it is necessary to introduce a signal system in order to authorize the waste handling from the treatment centers and from the distribution centers to the supermarkets.

In this work the WEEE are categorized into:

- the disposed products coming from large scale organized distribution and deriving from one-toone basis purchases;

- the disposed products coming on a one-to-one basis from specialized shops not belonging to any organized distribution chain, and those not linked with the purchase of any new equipment.

The collection centers operation has been partly transformed. In fact, they receive the second category of products, managed still in a push manner: as the container is filled, the waste is not sent anymore to the treatment center but to the supermarket. On the other hand, the operation of the treatment center has been substantially modified: it is now responsible for the waste withdrawal request. So, an information flow occurs between the process center and the supermarkets. As a certain threshold is reached, the treatment center sends a supply request to the supermarkets which satisfy this request based on their inventory levels. At this point a milk-run is triggered to collect WEEE from the various supermarkets. A Kanban Table is used to generate requests by the treatment center: the supply requests are always generated based on inventory level in order to minimize the average stock and to avoid stock-out. The milk-run logic is to withdraw a default percentage from the various supermarkets. At this point, an information system will change, if necessary, these percentages to satisfy the demand. The WEEE flow management model based on a push/pull hybrid logic has been implemented through the I-Think® software (http:/www.iseesystems.com/community/support/support.aspx). To take into consideration some system peculiarities, the simulation model has been structured in different sub models. The full model's structure is represented in Figure 3.

In particular, the sub models are relative to:

- Treatment center

- The process of determination the vehicles number

- The waste generation process

Two different possibilities have been considered for the waste arrivals. The first one considers a push strategy for the dispatch management: when the maximum capacity of a distribution center is reached, $5 \%$ of stocked WEEE is sent. The second possibility, on the other hand, is based on a pull strategy: in order to replenish its stocks, the supermarket sends a handling signal to the distribution center requiring the same amount drawn by the treatment center and respecting the constraint of the maximum transportable load during each milk-run. 


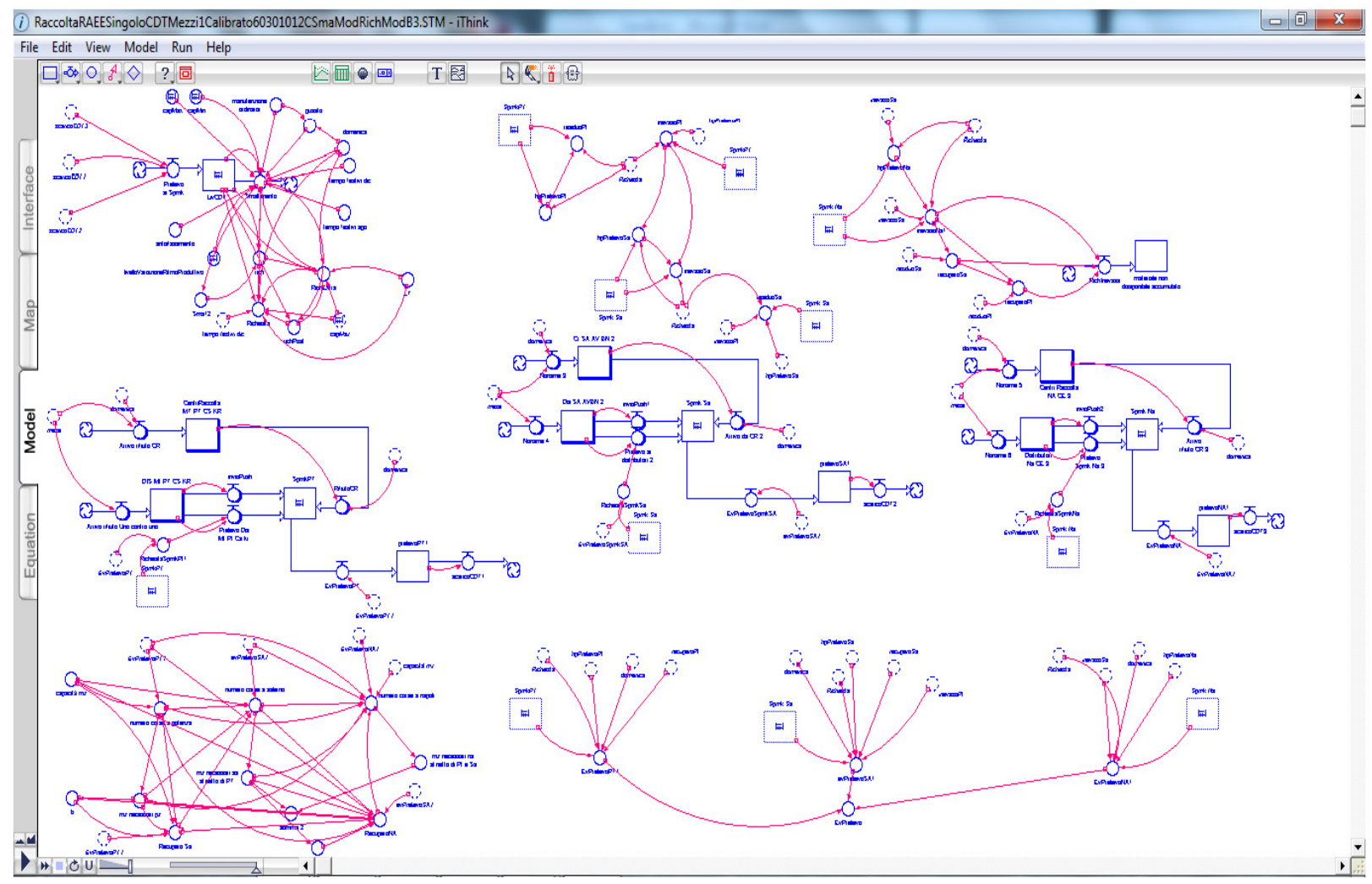

Figure 3: I-Think ${ }^{\circledR}$ system model

\section{ANALYSIS OF RESULTS}

We analyzed the system's behavior as a whole using selected metrics. In particular we have considered: the average inventory level, the inventory turnover index, the average re-order time, the average disposal rate, and the efficiency of facilities. We use the model with the push logic, i.e., the current model of waste flow management, as a benchmark (see Figure 4).

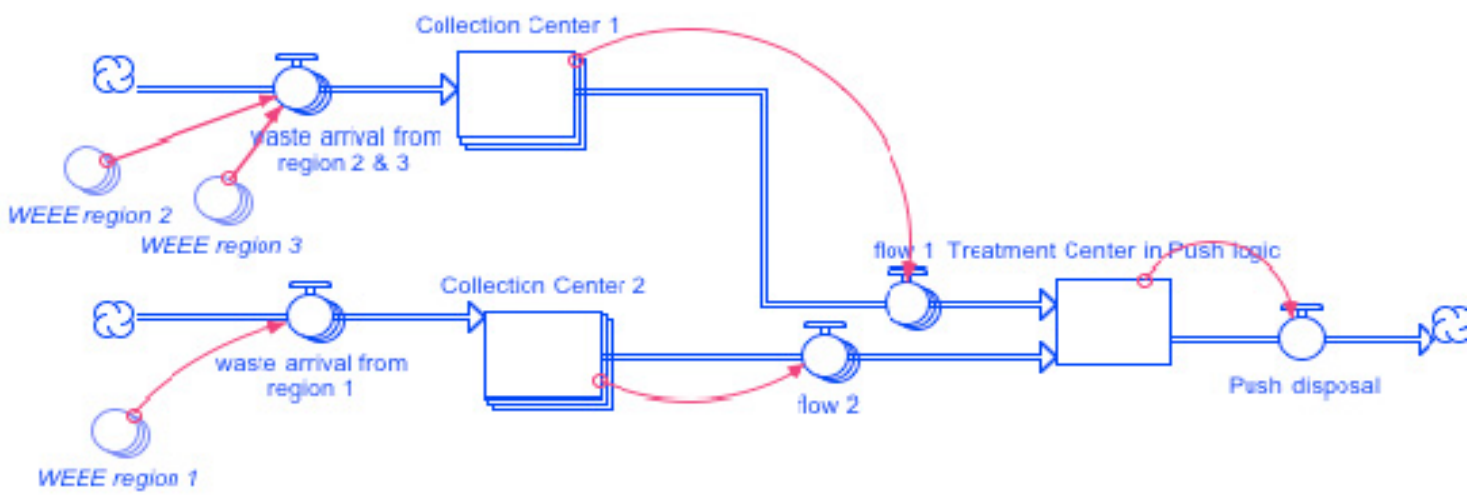

Figure 4: Push system's structure in I-Think ${ }^{\circledR}$

We assume a maximum disposal rate of 20 tons per day and an inventory capacity of about 45 tons. The "push" dispatches imply that each collection center pushes wastes to the treatment center once it reaches a threshold inventory level of $3500 \mathrm{Kg}$ (according to the freight transport vehicles capacity). The 
simulation results highlight a great discontinuity in WEEE flow producing a continual variation of stock and a high average disposal rate (see Figure 5).

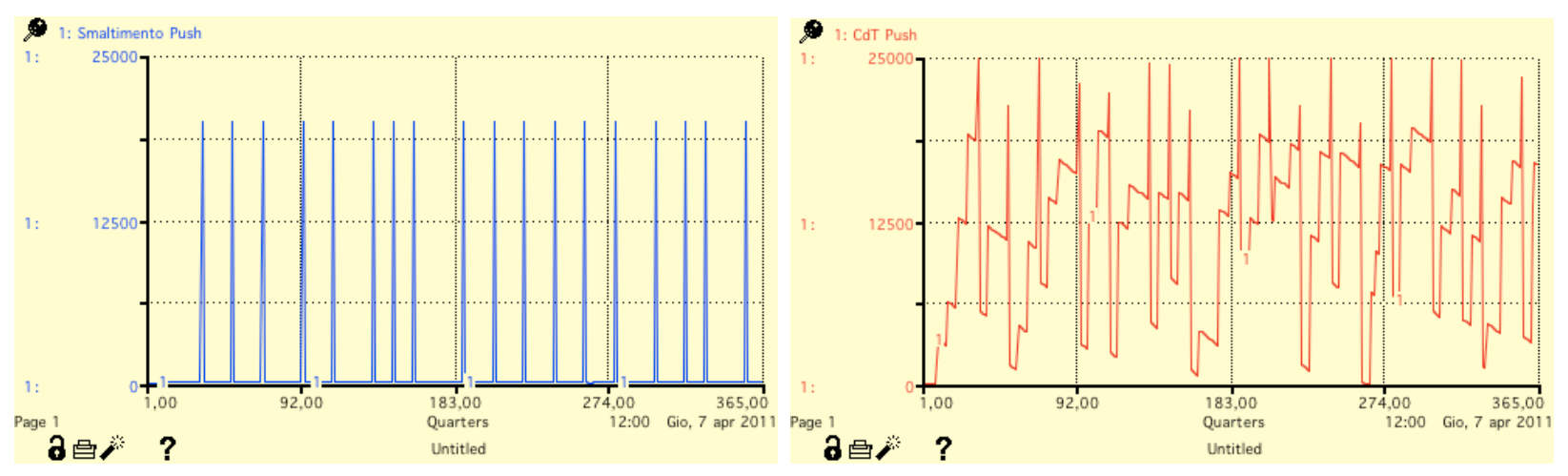

Figure 5: Treatment Centre's inventory level with Push Logic

In particular the average disposal rate is about $15,000 \mathrm{Kg} /$ day with reference to a maximum value, as above mentioned, of $22,500 \mathrm{~kg}$ per day. This determines a plant efficiency $\eta=0.60$.

The proposed logic, instead, allows achieving a WEEE continuous flow, which ensures a better performance for the treatment center. Figure 6 shows the inventory level and the disposal rate at the treatment center, and Figure 7 the simultaneous variation of supermarkets. We highlight that both treatment center disposal and the stock level are lower, in absolute value, than previous case (push system) and pulse with the downstream demand. In other words the treatment operation is activated only if there is a downstream request. Then we take materials (WEEE) from warehouse to start dismantling products and simultaneously we send, based on the kanban board, supermarket replenishment order.
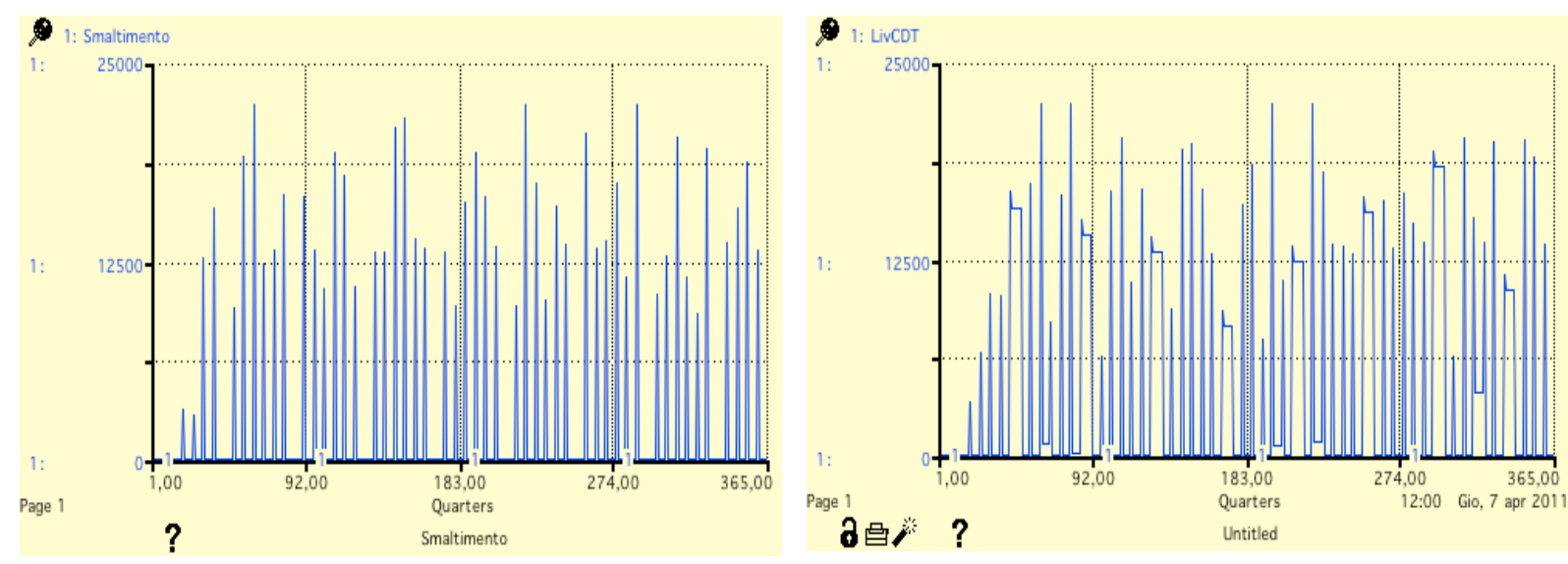

Figure 6: Treatment center inventory level with a hybrid Push/Pull logic

For the inventory turnover calculation, the following formula has been used:

$$
I_{R}=\frac{\text { CumulativeDisposal }}{A V_{-} \text {Inv }} \quad\left[\frac{\text { Days }}{\text { Year }}\right]
$$




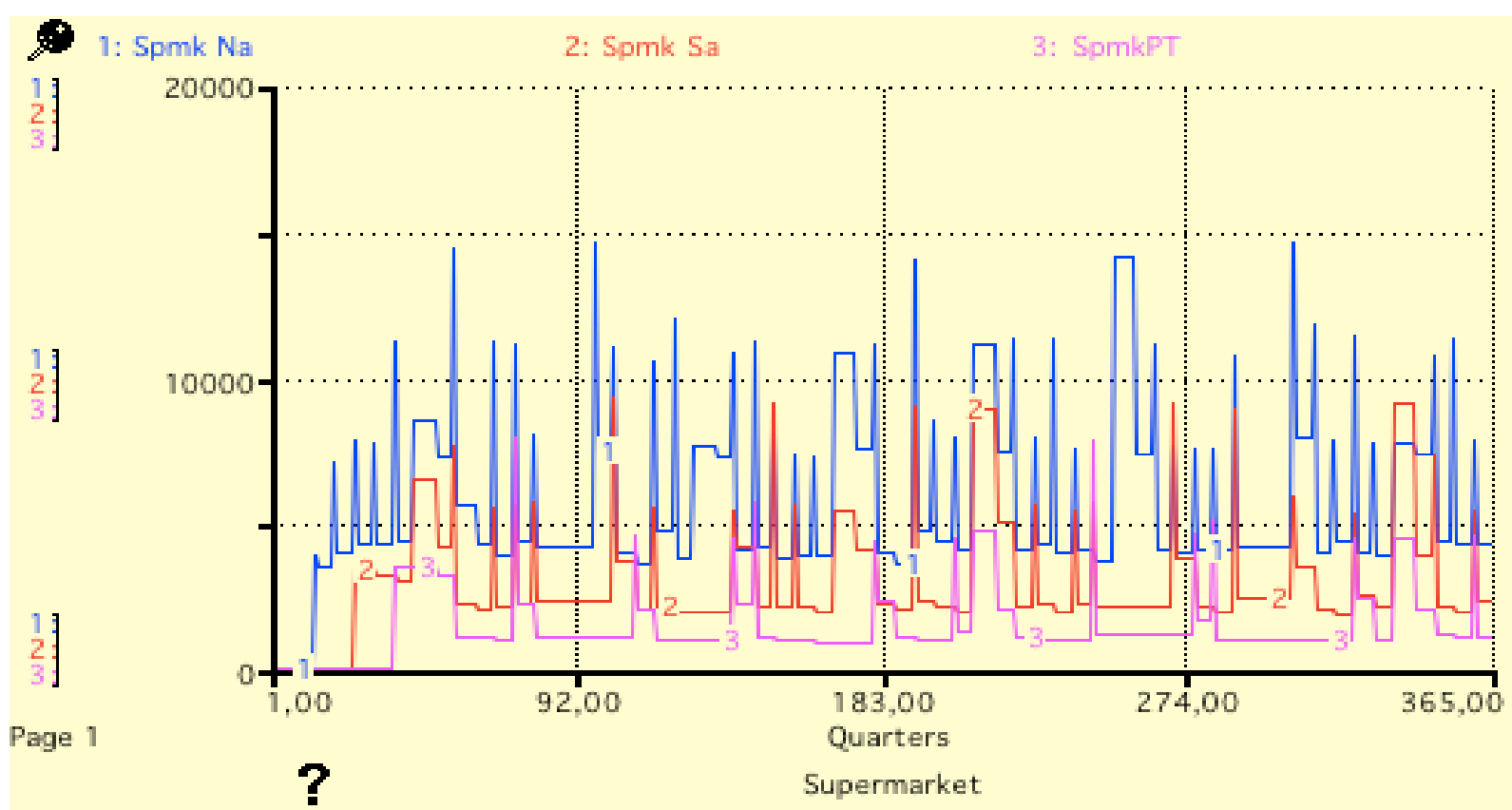

Figure 7: Supermarket inventory level with a hybrid Push/Pull logic

Where AV_Inv is the average inventory level and it is calculated as follows:

$$
A v_{-} \text {inv }=\frac{\text { CumulativeInventory }}{365 \text { days }} \quad\left[\frac{\mathrm{kg}}{\text { days }}\right]
$$

In our case IR has a value of 205.98. Then it is possible to determine the average inventory time at the treatment center through the following formula:

$$
T=\frac{365 \text { days }}{A v_{-} \text {inv }} \quad[\text { days }]
$$

The value of $T$ is 1.77 days and the efficiency calculated is $\eta=0.95$.

The Supermarkets' performance is captured using three measures: the average inventory level, the average inventory time and the turnover index. The values obtained are summarized in Table 2.

Table 2: Performance Measures of the Push/Pull hybrid system

\begin{tabular}{rrrr}
\hline Av_inv [kg/days] & $\mathrm{T}$ [days] & $\mathrm{I}_{\mathrm{R}}$ [days/year] \\
\hline Spmk 1 & 9218.43 & 3.50 & 104.23 \\
Spmk 2 & 25195.87 & 5.40 & 67.51 \\
Spmk 3 & 121810.9 & 12.19 & 29.92 \\
Collect_center & 14070.57 & 1.51 & 241.11 \\
Market Distribution & 213717.9 & 26.05 & 14.01
\end{tabular}




\section{Gallo, Romano, and Santillo}

From these results we can deduce potential marked improvements in WEEE management. In fact, this new management model allows for an average inventory time of 20.8 days, weighted among the various collecting centers (large scale organized distribution and the supermarkets), while for the current management model an average inventory time of 28.3 days has been estimated (a reduction of $26.5 \%$ ). Finally, a reduction in the average inventory level of $18 \%$ can be highlighted. The average time between two consecutive requests, i.e., the rate at which the system generates supply requests to supermarkets, is equal to 1.01 days. In Table 3 the requests of the treatment center, classified by typology, are reported.

Table 3: Request sorting to the treatment center

\begin{tabular}{lr}
\hline Request Typology & Quantity \\
\hline Normal Requests & 259 \\
Red zone requests & 33 \\
Total requests & 292 \\
\hline
\end{tabular}

In order to fulfill the supply requests on time 4 freight transport vehicles are needed at most. In particular, from an analysis of available data it can be argued that this number of vehicles is sufficient in $79 \%$ of cases.

\section{CONCLUSIONS AND FUTURE DEVELOPMENTS}

The present work makes an analysis of WEEE collection system with the aim of highlighting its criticisms and then proposing improvements to make it more efficient and effective. We start from the actual management models of WEEE recovery networks tracing the Current State Map, which shows that the duration of storage at collection centers is the major critical issue, reducing the profitability and expectations of an efficient recovery of waste. The importance and, then, the necessity of WEEE recovery are due to their disposal rate. Today, only about $27 \%$ of these products are recovered and so subtracted from a landfill disposal, with the imaginable consequences on environment. Noting that natural resources are limited and that disposed products can be returned to the market as raw material or remanufactured, some actions are taken on the current management model using the basic concepts of Lean Production. So following a push/pull approach, the pacemaker process for the whole collecting system is shown to be the treatment center that according to its needs pulls the right amount of waste from Supermarkets, in turn replenished by the collecting centers. The Supermarkets decouple the process, since there is not a continuous flow between the upstream collecting and the downstream treatment of products. Moreover, the introduction of Supermarkets allows for a more centralized RAEE management, from a logistical point of view, with respect to the current strongly decentralized structure found to be less efficient. A request from the treatment center is satisfied by collecting WEEE at various Supermarkets according to a milk run logic. Using the simulation software I-Think ${ }^{\circledR}$ the aforesaid logic is implemented by creating a simulation model of the system. This model allows evaluating the lead time reduction by using the new management model to supply the treatment center; in particular a significant reduction in the waste storage time at the various collection centers is obtained. The treatment center also shows improvements in its manufacturing activities getting through the recycling process a recovery of secondary raw materials increased by $7 \%$ compared to the current situation (about 352 tons of iron, aluminum, copper and plastic). The proposed changes to the management model are reflected in the following changes to the current state map leading to the Future State Map depicted in Figure 8. 


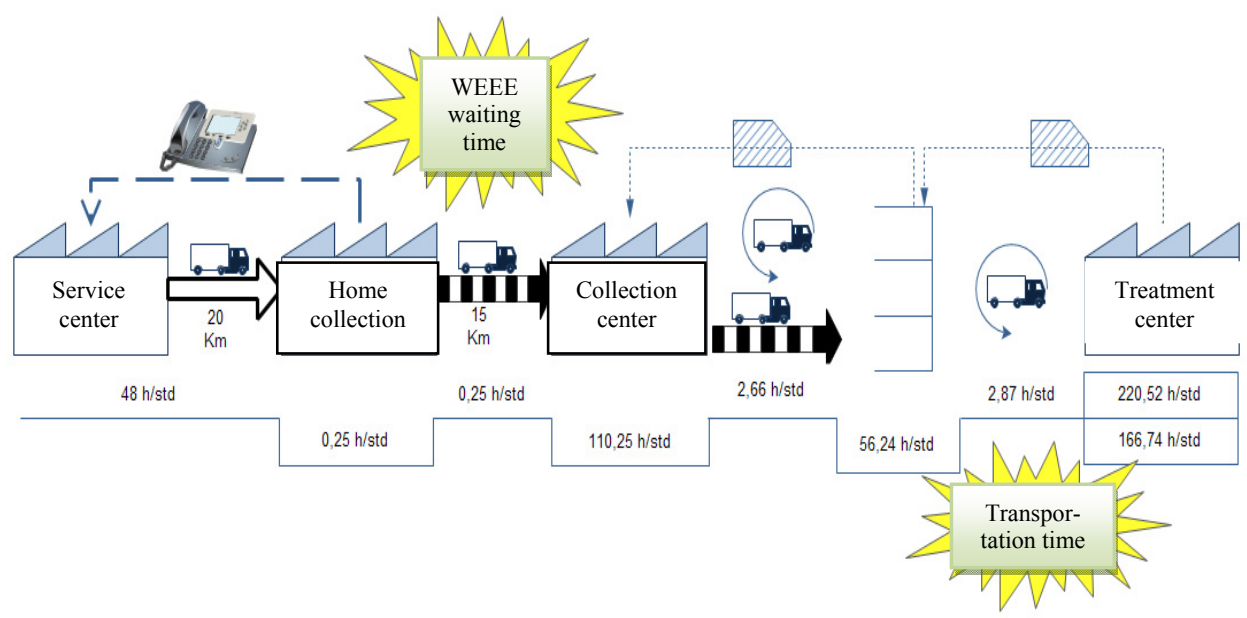

Figure 8: Future State Map

\section{REFERENCES}

Ammons, J., M. Realff, and Newton, D. 1997. "Reverse Production System Design and Operation for Carpet Recycling." Georgia Institute of Technology, Atlanta. Technical Report.

Berger, T., and B. Debaillie. 1996. "Location of Disassembly Centers for Re-Use to Extend an Existing Distribution Network." Master's thesis, University of Leuven, Belgium.

Fleischmann, M., R. Dekker, E. Van der Laan, J. Van Numen, L. Van Wassenhove, and Ruwaard J. 1997."Quantitative models for reverse logistics: a review.", European Journal of Operational Research, 103 1-17

Gallo, M., T. Murino, and E. Romano. 2010. "The Simulation of Hybrid Logic in Reverse Logistics Network." In Selected Topics in System Science and Simulation Engineering. 378-384. Japan: Wseas Press.

Georgiadis, P., and M. D. Besiou. 2008. "Sustainability in Electrical Electronic Equipment Closed-Loop Supply Chains: A System Dynamics Approach.” Journal of Cleaner Production 16:1665-1678.

Georgiadis, P., and D. Vlachos. 2004. "Decision Making in Reverse Logistics using System Dynamics." Yugoslav Journal of Operational Research 14(2):259-272.

Gonçalves P, J. Hines, and J. Sterman. 2005. "The Impact of Endogenous Demand on Push-Pull Production Systems." System Dynamics Review 21(3):187-216.

Guerra, L., T. Murino, and E. Romano. 2007. "A Heuristic Algorithm for the Constrained LocationRouting Problem." International Journal of Systems Applications, Engineering \& Development 1(4):146-154.

Guerra, L., T. Murino, and E. Romano. 2009. "Reverse Logistics for Electrical and Electronic Equipment: A Modular Simulation Model." In Proceeding of the 8th Recent Advances in System Science and Simulation in Engineering ICOSSSE 2009, 307-312. Italy: Wseas Press.

Haffez, K, M. Griffiths, J. Griffiths, and J. Naim. 1996. "System Design of a Two-Echelon Steel Industry Supply Chain.” International Journal of Production Economics 45(1-3):121-30.

Krikke, H.R., and A. Van Harten. 1999. "Reverse Logistics Network Re-Design for Copiers." Operational Research Spectrum 21(3):381-409.

Louwers, D., B. J. Kip, E. Peters, F. Souren, and S. D. P. Flapper. 1999.“A Facility Location Allocation Model for Re-Using Carpet Materials." Computers and Industrial Engineering 36(4):1-15.

Min, H, and W. P. Galle. 2001. "Green Purchasing Practices of US Firms." International Journal of Operations \& Production Management 21(9):1222-38. 
Rogers, D.S., and R. S. Tibben-Lembke, R.S. 1999. "Going Backwards: Reverse Logistics Trends and Practices." Reverse Logistics Executive Council, Pittsburgh, PA.

Shultmann, F., M. Zumkeller, and O. Rentz. 2006. "Modeling Reverse Logistics Tasks Within Closedloops Supply Chain: An Example from the Automotive Industry." European Journal of Operational Research 171:1033-1050.

Spengler, T., H. Duckert, T. Penkhun, and O. Rentz. 1997.."Environmental Integrated Production and Recycling Management." European Journal of Operational Research 97:308-326.

Towill, D. 1995. "Industrial Dynamics Modeling of Supply Chains." International Journal of Physical Distribution \& Logistics Management 26(2):23-42.

Van Schaik, A., and M. A. Reuter. 2004. "The Time-Varying Factors Influencing the Recycling Rate of Products." Resources, Conservation \& Recycling 40(4):301-28.

\section{AUTHOR BIOGRAPHIES}

MOSÈ GALLO has a PhD in "Production Systems and Technologies" (Department of Materials Engineering and Operations Management of the University of Naples "Federico II"). He also has a master degree in mechanical engineering from the same university. At the moment he is a contract researcher at the Department of Materials Engineering and Operations Management of the University of Naples "Federico II." He has several research interests related to the design and management problems of production systems. In particular he has studied issues concerning quality, maintenance, production planning, environmental sustainability, and soft computing techniques applied to industrial fields. He has authored several papers presented at international conferences and published in international journals of industrial engineering. His email address is mose.gallo@unina.it.

ELPIDIO ROMANO graduated in Transportation Engineering, and has a $\mathrm{PhD}$ in Transportation Systems and Theory. At the moment he is a contract researcher at the Department of Materials Engineering and Operations Management of the University of Naples "Federico II" Faculty of Engineering. He is a Tutor at "Uninettuno University." His research activities are mainly concerned about the following topics: Simulation modeling, Traffic and Transportation simulation and analysis, Maintenance strategies, Supply Chain Management models, Quick Response Manufacturing, Sustainable production processes, LocationRouting and vehicle routing Problem, Lean Service, and Lean production implementation. He has authored several papers presented at international conferences and published in international journals of industrial engineering. His e-mail is elromano@unina.it.

LIBERATINA CARMELA SANTILLO graduated in Mechanical Engineering, and is a Full Professor in the ING-IND 17, Industrial Plant System disciplinary group, in the Faculty of Engineering at University of Naples "Federico II." She teaches Safety and Security Management, Industrial and Mechanical Plants and Industrial Logistics at the Engineering Faculty. Her research activities are mainly concerned about the following topics: Safety and Security management models, Simulation modeling, Maintenance strategies, Supply Chain Management models, Quick Response Manufacturing, Sustainable production processes, Lean Service, and Lean production implementation. Her email address is santillo@unina.it. 